\title{
LA INCIDENCIA DEL ACUERDO DE PARÍS EN LAS POLÍTICAS PÚBLICAS CATALANAS FRENTE AL CAMBIO CLIMÁTICO: LA LEY 16/2017, DE 1 DE AGOSTO, DEL CAMBIO CLIMÁTICO'
}

\section{THE INCIDENCE OF THE PARIS AGREEMENT IN THE CATALAN PUBLIC POLICIES AGAINST THE CLIMATE CHANGE: THE ACT 16/2017, AUGUST $1^{\text {ST, OF THE CLIMATE CHANGE }}$}

\author{
MARINA RODRÍGUEZ BEAS
}

Profesora de Derecho Administrativo Universitat Rovira i Virgili

Investigadora

Centre d'Estudis de Dret Ambiental de Tarragona (CEDAT)

marina.rodriguez@urv.cat

Fecha de recepción: 21 de mayo de 2018 / Fecha de aceptación: 10 de octubre de 2018

RESUMEN: Este trabajo tiene como objetivo describir brevemente la incidencia del Acuerdo de París y las iniciativas impulsadas por la Unión Europea en la formulación y desarrollo de las políticas públicas catalanas respecto al cambio climático. Se pretende conocer cómo Catalunya ha ido incrementando su grado de implicación en esta materia durante los últimos años, hasta llegar a disponer de diferentes instrumentos y normas para afrontar los retos existentes en materia de mitigación y adaptación al cambio climático, de entre las que destacamos la Ley 16/2017, de 1 de agosto, del cambio climático. Asimismo, se pretende describir y analizar la citada norma con rango de ley que se ha convertido en el eje vertebrador de las políticas públicas de Catalunya en este ámbito. Con esta

\footnotetext{
${ }^{1}$ El presente estudio ha sido realizado en el marco del proyecto de investigación "Constitución climática global: gobernanza y derecho en un contexto complejo" (referencia DER2016-80011P), financiado por el Ministerio de Economía y Competitividad, dentro del Programa Estatal de Fomento de la Investigación Científica y Técnica de Excelencia, Subprograma Estatal de Generación del Conocimiento, en el marco del Plan Estatal de Investigación Científica y Técnica y de Innovación 2013-2016.
} 
finalidad, se identifican, en primer lugar, los objetivos de mitigación y de adaptación que determina la Ley; en segundo lugar, los objetivos de reducción de emisiones de gases de efecto invernadero que se definen como propios; y finalmente, los mecanismos de adaptación al cambio climático, con especial referencia a los instrumentos de planificación y programación.

RESUM: Aquest treball té com a objectiu descriure breument la incidència de l'Acord de París i les iniciatives impulsades per la Unió Europea en la formulació i desenvolupament de les polítiques públiques catalanes respecte al canvi climàtic. Es pretén conèixer com Catalunya ha anat incrementant el seu grau d'implicació en aquesta matèria durant els últims anys, fins arribar a disposar de diferents instruments i normes per afrontar els reptes existents en matèria de mitigació i adaptació al canvi climàtic, d'entre les que destaquem la Llei 16/2017, d'1 d'agost, del canvi climàtic. Així mateix, es pretén descriure i analitzar l'esmentada norma amb rang de llei que s'ha convertit en l'eix vertebrador de les polítiques públiques de Catalunya en aquest àmbit. Amb aquesta finalitat, s'identifiquen, en primer lloc, els objectius de mitigació i d'adaptació que determina la Llei; en segon lloc, els objectius de reducció d'emissions de gasos d'efecte hivernacle que es defineixen com a propis; i finalment, els mecanismes d'adaptació al canvi climàtic, amb especial referència als instruments de planificació i programació.

ABSTRACT: The objective of this paper is describe the impact of the Paris Agreement and the initiatives promoted by the European Union in the formulation and development of Catalan public policies regarding climate change. It is intended to know how Catalonia has been increasing its level of involvement in this area during the last years, until it has had different instruments and norms to face the existing challenges in terms of mitigation and adaptation to climate change, among which we highlight the Law 16/2017, of August 1, on climate change. Likewise, it is intended to describe and analyze the aforementioned standard with the status of a law that has become the backbone of the public policies of Catalonia in this area. To this end, the mitigation and adaptation objectives determined by the Law are identified in the first place; secondly, the 
objectives of reducing emissions of greenhouse gases that are defined as their own; and finally, the mechanisms of adaptation to climate change, with special reference to planning and programming instruments.

PALABRAS CLAVE: cambio climático - políticas públicas - ley - mitigación - adaptación - planificación - objetivos de reducción - Comunidades Autónomas.

PARAULES CLAU: canvi climatic - polítiques publiques - llei - mitigació adaptació - planificació — objectius de reducció - Comunitats Autònomes.

KEYWORDS: Climate change - public politics - law - mitigation - adaptation — planning — reduction objectives - autonomous communities.

SUMARIO: 1. Introducción. 2. El papel de Catalunya como "subnational entity". 3. Las políticas públicas catalanas frente al cambio climático: antecedentes y situación actual. 4. La iniciativa legislativa catalana: la Ley 16/2017, de 1 de agosto, del cambio climático. 4.1. Los objetivos de mitigación y de adaptación. 4.2. La mitigación del cambio climático. 4.2.1. Los objetivos de reducción de emisiones de gases de efecto invernadero. 4.3. La adaptación al cambio climático: marco estratégico de referencia e instrumentos de planificación y programación. 4.4. Conflicto competencial: la impugnación de la Ley de cambio climático ante el Tribunal Constitucional. 5. Conclusiones. 6. Bibliografía

\section{INTRODUCCIÓN}

El problema del cambio climático tuvo su primer reconocimiento internacional en 1992 al aprobarse el Convenio Marco de las Naciones Unidas sobre cambio climático, que permitió en 1997, la firma del Protocolo de Kyoto, con el fin de limitar el crecimiento y lograr una estabilización de las concentraciones de gases con efecto invernadero (GEI) en la atmósfera. Las sucesivas Conferencias de las Partes (COP) han realizado el seguimiento del cumplimiento del Protocolo y a la vez han ido estableciendo las diversas líneas de actuación que deben guiar las políticas públicas para conseguir reducir las emisiones de gases con efecto invernadero y, a la vez, prever estrategias en las zonas más vulnerables a los impactos del cambio climático. 
Siguiendo estos mismos objetivos, el 12 de diciembre de 2015, la Conferencia de las Partes del Convenio Marco de las Naciones sobre el Cambio Climático (COP21) y la reunión de las Partes del Protocolo de Kyoto (COP-MOP11) adoptaron el llamado Acuerdo de París, el cual marca la hoja de ruta de la mitigación y la adaptación al cambio climático durante los próximos años ${ }^{2}$. Con la adopción de este acuerdo se consolida la actuación iniciada formalmente en el Convenio Marco de las Naciones Unidas sobre el cambio climático, durante los próximos años y ya no se cuestiona la existencia del calentamiento global. De este modo, el 2015 se convirtió en un año clave a nivel internacional para el desarrollo sostenible y el cambio climático ${ }^{3}$.

La adopción del Acuerdo de París y las iniciativas impulsadas por la Unión Europea ${ }^{4}$ tienen relevantes implicaciones jurídicas que afectan a la formulación

\footnotetext{
2 Véase, entre otros, LAGO CANDEIRA, A., "Compromisos Internacionales ambientales: Agenda 2030 y Objetivos de Desarrollo Sostenible (incluidos los de cambio climático)", LÓPEZ RAMÓN, F. (coord.), Observatorio de políticas ambientales 2016, Centro de Investigaciones Energéticas, Medioambientales y Tecnológicas, CIEMAT, 2016, pp. 25-64. LAGO CANDEIRA, A., "EI Acuerdo de París. ¿Solución al cambio climático o el principio del fin del actual multilateralismo ambiental?, Ambienta: La revista del Ministerio de Medio Ambiente, núm. 114, 2016, pp. 20-32. SALINAS ALCEGA, S., "El Acuerdo de París de diciembre de 2015: la sustitución del multilateralismo por la multipolaridad en la cooperación climática internacional", Revista española de derecho internacional, vol. 70, núm. 1, 2018, pp. 53-76. FAJARDO DEL CASTILLO, T., "EI acuerdo de París sobre el cambio climático: sus aportaciones al desarrollo progresivo del Derecho internacional y las consecuencias de la retirada de los Estados Unidos", Revista española de derecho internacional, vol. 70, núm. 1, 2018, pp. 23-51. PONT I CASTEJÓN, I.; CAMPINS ERITJA, M.; NIETO MORENO, J. E., "Epíleg jurídic: De Kyoto a París. Escenaris i reptes futurs en la política internacional de canvi climàtic", Tercer informe sobre el canvi climàtic a Catalunya, Generalitat de Catalunya, Institut d'estudis catalans, Barcelons, 2016, pp. 597-612. LABANDEIRA VILLOT, X., "Cambio climático: el camino desde París", Administración \& ciudadanía: revista da Escola Galega de Administración Pública, vol. 11, núm. 2, 2016, pp. 221 224. JIMÉNEZ HERRERO, L. M., "El Acuerdo climático de París: bases para una descarbonización profunda en una perspectiva europea y española", Administración \& ciudadanía: revista da Escola Galega de Administración Pública, vol. 11, núm. 2, 2016, pp. 227242. OLABE EGAÑA, A., "Tras el Acuerdo de París: elementos para una estrategia de salida a la crisis del clima", Administración \&ciudadanía: revista da Escola Galega de Administración Pública, vol. 11, núm. 2, 2016, pp. 263-280. DE LA CRUZ LEIVA, J. L., "La transición hacia una economía baja en carbono: una oportunidad para el clima y el empleo". Administración \& ciudadanía: revista da Escola Galega de Administración Pública, vol. 11, núm. 2, 2016, pp. 281 304. SARASÍBAR IRIARTE, M., "La Cumbre del Clima de París: ¿un avance importante en la política del cambio climático?, Administración \& ciudadanía: revista da Escola Galega de Administración Pública, vol. 11, núm. 2, 2016, pp. 307-314.

3 Véase, MOVILLA PATEIRO, L., "2015, Un año clave a nivel internacional para el desarrollo sostenible, el cambio climático y el agua", Revista de derecho, agua y sostenibilidad, 2016, núm. 0, pp. 1-8, <http://redas.webs.uvigo.es/index.php/es/suscriptores/45-2015-un-ano-clave> [Última consulta, 16 de mayo de 2018].

${ }^{4}$ Entre las iniciativas más relevantes destacan: la Directiva 2003/87/CE del Parlamento Europeo y del Consejo, de 13 de octubre de 2013, por la que se establece un régimen del comercio de derechos de emisión de GEI en la Comunidad y por la que se modifica la Directiva 96/61/CE del Consejo; en el año 2009, el Consejo de Europa adopta el conocido Paquete Energía y Clima que asume el triple compromiso para el año 2020 de incrementar el uso de las energías renovables
} 
y desarrollo de las políticas de los Estados ${ }^{5}$, pero también a las entidades subestatales, como es el caso de Catalunya, respecto al cambio climático ${ }^{6}$.

El cambio climático es uno de los grandes retos del siglo $\mathrm{XXI}^{7}$. Todos los territorios muestran evidencias del cambio climático. En Catalunya también es un tema relevante por la importancia de los impactos observados y proyectados en el bienestar y en su economía.

La temperatura media anual en Catalunya ha aumentado 1,55 grados desde 1950, año a partir del cual se empieza a disponer de una red completa de observatorios meteorológicos, y del orden de dos grados desde 1990. El cambio puede parecer escaso o difícil de apreciar en la vida cotidiana, pero la realidad es que esto ha supuesto, entre muchos otros efectos, un ligero incremento del nivel del mar, una recurrencia más grande a las oleadas de calor y de los periodos de sequía, un cambio de las especies, una regresión de las playas, la desaparición de los últimos glaciares, un cambio de fecha en la floración y la fructificación de los cultivos y un retroceso en la montaña de las especies

\footnotetext{
hasta un $20 \%$ del consumo ruto de energía final, reducir en un $20 \%$ el consumo de energía primaria gracias a un incremento de la eficiencia energética y reducir las emisiones de gases de efecto invernadero un 20\% en el horizonte del año 2020 en relación con el año 1990; en el año 2013 se aprobó la Estrategia europea de adaptación al cambio climático que establece las bases y prioridades para actuar en todos los niveles de la administración, europea, nacional y local para convertirse en menos vulnerables ante los impactos del cambio climático; la Estrategia Europa 2020 es el instrumento que determinas unos hitos de crecimiento de la UE para la próxima década, con la finalidad no sólo de superar la crisis económica sino de corregir nuestro modelo de crecimiento y conseguir un crecimiento sostenible basado en una economía baja en carbono; la Decisión UE 2015/1814, de 6 de octubre; la Decisión 2015/146, de 26 de enero; y la Decisión 205/1339, de 13 de julio de 2015.

${ }^{5}$ VERDÚ BAEZA, J. "Retos para España y la Unión Europea en la lucha contra el cambio climático: el complicado camino hacia París 2015. Nuevos paradigmas de cooperación transfronteriza en el Estrecho", ALCAIDE FERNÁNDEZ, J.; PETIT DE GABRIEL, E. (Coords.), España y la Unión Europea en el orden internacional: XXVI Jornadas ordinarias de la Asociación Española de Profesores de Derecho internacional y Relaciones internacionales, Universidad de Sevilla, 15 y 16 de octubre de 2015.

${ }^{6}$ Sobre esta cuestión véase, entre otros, GARCÍA LUPIOLA, A., "La política medioambiental de la unión europea ante el cambio climático", Revista Electrónica de Derecho Ambiental, 2009, núm. 18; ABBAS, MEDí, "Politiques de I'Union. La proposition d'une taxe $\mathrm{CO} 2$ aux frontières. Vers une stratégie européenne en matière de régulation commerciale et de lutte contre le changement climatique?", Revue du marche commun et de l'Union Européenne, 2007, núm. 513, pp. 628-637;

7 Sobre el reto que supone para el derecho público el cambio climático véase, entre otros, PAREJO ALFONSO, L., (dir.), El Derecho Ante la Innovación y los Riesgos Derivados del Cambio Climático, Valencia, Tirant lo Blanch, 2015. RUIZ DE ELVIRA, A., "Contra el cambio climático, un cambio de mente", Ambienta: La revista del Ministerio de Medio Ambiente, núm. 114, 2016.
} 
forestales más típicas de ambientes fríos ${ }^{8}$. El tercer Informe sobre cambio climático analiza cómo afecta en Catalunya, concretando cinco elementos de primer orden que pueden relacionarse con el cambio climático o calentamiento global. Estos cinco elementos son: a) el número de días nublados ha aumentado con el calentamiento global en Catalunya durante los meses de verano; b) las transformaciones en los cultivos; c) el nivel del mar en la costa catalana ha subido 10 centímetros en los últimos 30 años, 7 de los cuales en los últimos años; d) una mayor irregularidad pluviométrica puede conllevar incendios forestales imposibles de parar sino se gestionan las masas arbóreas ${ }^{9}$.

En este contexto, dotarse de una norma con rango de ley que alcance la mitigación y la adaptación al cambio climático puede ser eficaz para fijar un marco jurídico que ofrezca seguridad y estabilidad a los instrumentos de planificación y a las actuaciones de los poderes públicos, llevadas a cabo en los últimos años. Además, este instrumento legislativo puede consolidar la actuación de Catalunya ante el cambio climático. Así, con la aprobación de la Ley 16/2017, de 1 de agosto, del cambio climático, Catalunya da un paso significativo para establecer los fundamentos legales de la política de reducción de las emisiones de GEI (mitigación) y de reducción de la vulnerabilidad a los efectos del cambio climático (adaptación).

Este trabajo tiene como objetivo describir brevemente la incidencia del Acuerdo de París y las iniciativas impulsadas por la Unión Europea en la formulación y desarrollo de las políticas públicas catalanas respecto al cambio climático, pero, sobre todo, describir y analizar la norma con rango de ley que se ha convertido en el eje vertebrador de las políticas públicas de Catalunya en este último ámbito, es decir, la Ley 16/2017, de 1 de agosto, del cambio climático.

\section{EL PAPEL DE CATALUNYA COMO "SUBNATIONAL ENTITY"}

\footnotetext{
8 Una aproximación a la problemática actual desde el ámbito físico la encontramos en RUIZ DE ELVIRA, A., "Contra el cambio climático, un cambio de mente", Ambienta: La revista del Ministerio de Medio Ambiente, 2016, núm. 114.

9 Tercer informe sobre el canvi climàtic a Catalunya, Institut d'Estudis Catalans y la Generalitat de Catalunya, Barcelona, 2016.

<http://cads.gencat.cat/web/.content/Documents/Publicacions/tercer-informe-sobre-canviclimatic-catalunya/Sintesis/CC_Sintesi-CASTELLA_web.pdf> [Última consulta, 15 de mayo de 2018]).
} 
Dentro del marco internacional y de la Unión Europea, los compromisos en materia de cambio climático, tanto en el ámbito de la mitigación como de la adaptación, se han establecido siempre en el ámbito de los Estados, en una construcción de arriba hacia abajo (top-down).

No obstante, en los últimos años, tanto las Naciones Unidas como la Unión Europea $^{10}$ han reconocido el papel fundamental de los gobiernos regionales y locales en el éxito de la política climática y cada vez se configura con más fuerza una construcción de abajo hacia arriba (bottom-up), el cual se fundamenta en el nivel competencial, de responsabilidad y de intervención de los entes subestatales ${ }^{11}$. Efectivamente, en la $22^{2}{ }^{a}$ Conferencia de las Partes, celebrada en Marrakech a finales del año 2016, ya se hizo una llamada específica a los llamados organismos subestatales ${ }^{12}$ - ciudades y regiones-, a adherirse a los objetivos del Acuerdo de París y a presentar planes de reducción de emisiones para el año $2050^{13}$.

Por tanto, las Comunidades Autónomas, como entidades subestatales "subnational entities"-, juegan un papel muy importante para lograr los objetivos marcados por la Unión Europea en materia de cambio climático. A pesar que los compromisos y los objetivos fijados a nivel internacional y de la Unión Europea en materia de cambio climático solo son exigibles al Estado, las Comunidades Autónomas disponen de un elevado nivel competencial en diferentes ámbitos que les permite adoptar regulaciones propias, asumir compromisos y facilitar la aplicación de la normativa climática establecida a nivel internacional y de la

\footnotetext{
${ }^{10}$ En el Acuerdo de París también se reconoce este papel, a la luz de lo dispuesto en los párrafos 134 y 135.

11 Sobre el papel de los entes locales en la lucha contra el cambio climático, entre otros véase, BAÑO LEÓN, J. M., REVUELTA PÉREZ, I., "Cambio climático y Administración local", Revista Democracia y Gobierno Local, núm. 33, 2016, pp. 5-11. NAVARRO RODRíGUEZ, P., MORENO REBATO, M., "Nuevas medidas locales de lucha contra el cambio climático, especialmente en Andalucía", Revista de derecho urbanístico y medio ambiente, núm. 51, 2017, pp. 113-139. GALERA RODRIGO, S., GÓMEZ ZAMORA, M. M. (coord.), Políticas locales de clima y energía. Teoría y práctica. Instituto Nacional de Administración Pública, 2018. BORRÀS PENTINAT, S., "Ciudades y cambio climático: responsabilidades, retos y oportunidades", Revista Democracia y Gobierno Local, núm. 33, 2016, pp. 12- 14. FAUTH, G., RODRÍGUEZ BEAS, M., "Políticas de adaptación al cambio climático: especial referencia al pacto de alcaldes", en BORRÀS PENTINAT, S., VILLAVICENCIO CALZADILLA, P. (coord.), Retos y Realidades de la Adaptación al Cambio Climático. Perspectivas técnico-jurídicas, Aranzadi, Navarra, 2013, pp. 237-262.

12 VERDÚ BAEZA, J., "A propósito de la cumbre climática de Marrakech: Cuando la solución empieza a ser parte del problema", Revista electrónica de estudios internacionales, núm. 33, 2017.

${ }^{13}$ Se anunció la 2050 Pathways Platform.
} 
Unión Europea. Este es el caso de Catalunya, que al tener atribuidas competencias en la materia, tiene una gran capacidad para incidir tanto en el nivel de las emisiones de GEI -especialmente sobre las emisiones difusas-, como en las medidas de adaptación a los impactos sobre el territorio de la Comunidad Autónoma, los sistemas físicos y los sectores socio económicos más vulnerables a los impactos del cambio climático.

Desde esta perspectiva, cabe destacar que las Comunidades Autónomas, aunque no pueden ser consideradas sujetos de derecho internacional, si son actores internacionales. En este sentido, el magistrado Xiol Ríos afirma en el voto particular que formula en la STC 228/2016, de 22 de diciembre que el concepto de actor internacional:

"[...] no se define, ni se identifica por su subjetividad internacional, sino por las funciones que realiza y, sobre todo, por su capacidad para movilizar recursos que le permitan alcanzar unos objetivos que formula con cierta autonomía, ejerciendo su influencia sobre otros actores internacionales". Si bien no son sujetos internacionales, "[...] las Comunidades Autónomas, como las regiones y los entes locales en otros sistemas jurídicos, son considerados como actores subestatales o como actores gubernamentales no centrales que pueden desarrollar actividad con proyección internacional. Esta proyección, en el marco de nuestro ordenamiento jurídico, no ha de estar supeditada a lo que "permita" el Estado [...], sino al reparto de competencias que se establece en las normas que integran el bloque de la constitucional y entre las que no puede incluirse la Ley 2/2014, de 25 de marzo, de la acción y del servicio exterior del Estado".

Por tanto, en materia de cambio climático, las Comunidades Autónomas, como actores internacionales pueden desarrollar un papel clave en la consecución de los compromisos y objetivos establecidos a nivel internacional y europeo. Además, las competencias en materia de medio ambiente y cambio climático que tienen atribuidas las Comunidades Autónomas, conllevan el derecho y la obligación, en el marco de sus obligaciones de llevar a cabo las actuaciones necesarias para contribuir al alcance los objetivos generales de la Unión Europea. 
En este contexto, y en ausencia de una Ley española de cambio climático ${ }^{14}$, la norma autonómica es el instrumento ideal para facilitar la aplicación real y efectiva de las normas del Derecho de la Unión Europea. Pero, esta gobernanza multinivel se debería reforzar por parte del Estado español repitiendo el mismo esquema que utilizó la Unión Europea para establecer objetivos territorializados entre los Estados miembros. Además, estos deberían ir acompañados de recursos económicos, como también realizó la Unión Europea con el reparto de los recursos económicos procedentes de la generalización del mecanismo de la subasta en la tercera fase del mercado de comercio de derechos de emisión.

\section{LAS POLÍtICAS PÚBLICAS CATALANAS FRENTE AL CAMBIO CLIMÁTICO: ANTECEDENTES Y SITUACIÓN ACTUAL}

En el contexto del ámbito internacional, europeo y estatal, en los últimos años destaca la actuación de los poderes públicos catalanes en materia de cambio climático. La Generalitat de Catalunya ha sido una Administración pionera y se ha situado a la vanguardia del impulso de las políticas climáticas desde el año $2006^{15}$.

En este sentido, se constata el intenso ejercicio de sus competencias utilizando una gran diversidad de instrumentos y en diversos ámbitos como el normativo ${ }^{16}$, el planificador, el programático, de ejecución y de organización administrativa. No obstante, cabe destacar que la política catalana se ha circunscrito especialmente en la planificación y la programación. Así, se ha optado por la adopción de planes, programes y estrategias que tratan desde diferentes perspectivas la materia relacionada con el cambio climático.

\footnotetext{
${ }^{14}$ Los ministerios de Agricultura y Pesca, Alimentación y Medio Ambiente y de Energía, Turismo y Agenda Digital abrieron el proceso de consulta pública previo a la elaboración del anteproyecto de Ley de Cambio Climático y Transición Energética. Esta consulta pública, que ha estado abierta desde el 18 de julio hasta el pasado 10 de octubre de 2017, ha recibido más de 350 propuestas. < http://www.lccte.gob.es/\#EntreTodos> [Última consulta, 16 de mayo de 2018].

${ }^{15}$ Año de creación de la Oficina Catalana del Cambio Climático.

16 Hasta la aprobación de la Ley 16/2017, la materia relacionada con el cambio climático había sido tratada por medio de normas de carácter sectorial. No obstante, también encontramos normas de carácter reglamentario, entre las que cabe destacar el Decreto 397/2006, de 17 de octubre, de aplicación del régimen de comercio de derechos de emisión de gases con efecto invernadero y de regulación del sistema de acreditación de verificadores de informes de emisiones de gases con efecto invernadero sobre el comercio de derechos de emisión de GEI.
} 
En el ámbito de la planificación, destaca el Plan Marco de Mitigación del Cambio Climático 2008-2012 ${ }^{17}$, el Plan de Energía y Cambio Climático (PECAC 20122020) y la Estrategia Catalana de Adaptación al Cambio Climático (ESCACC 2013-2020), aunque sin olvidar planificaciones o actuaciones de ámbito sectorial donde también se han abordado aspectos relativos al cambio climático ${ }^{18}$.

Pero es la aprobación de la Estrategia catalana de adaptación al cambio climático Horizonte 2013-2020 (ESCACC), en el año 2012, la que supuso un impulso para las políticas de adaptación ${ }^{19}$. Por primera vez, se disponía de un documento técnico que aglutinaba todo el conocimiento científico del momento sobre los impactos presentes y futuros del cambio climático sobre los sistemas naturales, territorios y sectores económicos de Catalunya ${ }^{20}$; así como una propuesta de medidas de adaptación.

EI ESCACC plantea hasta 182 medidas de adaptación a los impactos del cambio climático, bien sea mediante la generación y transferencia del conocimiento sobre adaptación, bien sea mediante el aumento de la capacidad adaptativa de los sistemas y sectores analizados. De estas 182 medidas, 30 son genéricas, mientras que las 152 restantes son específicas para los once sectores socioeconómicos y sistemas naturales estudiados.

La ESCACC determina que la evaluación y el seguimiento de la Estrategia y de los planes correspondientes lo realizará la Oficina Catalana del Cambio Climático. Ante esta evaluación y seguimiento y con una periodicidad máxima de tres años, la Comisión Interdepartamental del Cambio Climático (CICC) elevará al Gobierno y al Parlamento un informe sobre el avance de la ESCACC y determina si debe realizarse una revisión. Para dar cumplimiento a esto, la Oficina Catalana del Cambio Climático elaboró, en diciembre de 2016, el

\footnotetext{
17 Aunque el objetivo de este Plan no es hacer un análisis de los impactos del cambio climático ni incorporar medidas de adaptación, sí que propone definir las políticas de mitigación para abordar de manera inmediata los análisis sectoriales y biofísicos que permitan definir una política efectiva de adaptación.

18 Algunos ejemplos son el Plan general de política forestal, el Plan estratégico de turismo, el Plan de desarrollo rural, entre otros.

19 El Gobierno de la Generalitat de Catalunya, mediante el Acuerdo 115/2012, de 13 de noviembre, aprobó la ESCACC.

20 Se incorporan en la ESCACC los análisis realizados conjuntamente entre el Servei Meteorològic de Catalunya y el Barcelona Supercomputing Center- Centre Nación de Supercomputación (BSC-CNS) sobre la generación de escenarios climáticos regionalizados para el período 2001-2050.
} 
documento "Seguiment i avaluació de l'Estratègia catalana d'Adaptació al Canvi Climàtic (ESCACC, Horitzó 2013-2020)"21, para informar a la CICC sobre el estado de adaptación a los impactos del cambio climático en Catalunya y el grado de implementación de la ESCACC ${ }^{22}$. La principal conclusión de este documento es que en Catalunya ha aumentado significativamente el conocimiento sobre los impactos del cambio climático. Este resultado se constata con varios indicadores:

- un $83 \%$ de las medidas genéricas y un $72 \%$ de las medidas específicas han sido iniciadas.

- Solo un $14 \%$ de las medidas genéricas y un $12 \%$ de las medidas específicas no han sido iniciadas.

- Las medidas genéricas del objetivo transversal $\mathrm{RDI}^{23}$ muestran una evolución satisfactoria, así como las correspondientes al objetivo transversal $\mathrm{NORM}^{24}$, aunque se observa un grado de avance insuficiente en las medidas genéricas del objetivo transversal OPOR ${ }^{25}$.

- Tres de los once sectores evaluados obtienen una calificación satisfactoria en cuanto a las medidas correspondientes a la generación y transferencia del conocimiento (gestión forestal, salud, y urbanismo y vivienda); seis sectores han avanzado, pero deben mejorar; y solo en dos sectores todavía no se ha realizados actuaciones (industria, servicios y comercio y turismo).

De la primera conclusión, en el propio documento, se extrae que el aumento de la capacidad adaptativa muestra unos avances claramente insuficientes. Los indicadores que alegan para confirmar esta segunda conclusión:

- Solo en gestión del agua se ha avanzado satisfactoriamente en el aumento de capacidad adaptativa; en cinco sectores falta mejorar y en los otros cinco el avance es imperceptible.

\footnotetext{
${ }^{21} \mathrm{http}: / /$ canviclimatic.gencat.cat/web/.content/home/politiques/politiques_catalanes/ladaptacio_a I_canvi_climatic/ESCACC/docs/Avaluacio-i-seguiment-de-IESCACC_febrer17.pdf [Última consulta, 15 de mayo de 2018]).

22 El citado documento fue aprobado por la CICC el 13 de febrero de 2017.

${ }^{23}$ Código del Objetivo Transversal: investigación, desarrollo e innovación.

${ }^{24}$ Codigo del Objetivo Transversal: normativo.

25 Codigo del Objetivo Transversal: oportunidad.
} 
- Algunas planificaciones sectoriales, como la forestal y la urbanística, han empezado a considerar los aspectos de la adaptación al cambio climático como factores clave a tener en cuenta en los próximos años.

- Se observa una falta clara de internalización de los costes ambientales en la industria agroalimentaria, lo que genera un avance insatisfactorio de la capacidad adaptativa de este sector.

- Se constata una falta de implicación del sector privado en la implementación de medidas de adaptación que reduzcan la vulnerabilidad de los sectores en los impactos del cambio climático.

De las dos conclusiones anteriores, se desprende una tercera: el objetivo estratégico del ESCACC en el horizonte del año 2020, es conseguir ser menos vulnerables a los impactos del cambio climático. La capacidad adaptativa de Catalunya necesita seguir mejorando, a pesar del conocimiento adquirido en los últimos años y la multitud de medidas y acciones iniciadas.

También se ha adelantado de manera muy relevante en el ámbito de la autorregulación mediante el Programa de Acuerdos Voluntarios para la reducción de emisiones. A través de este programa, los organismos se comprometen voluntariamente a elaborar cada año un inventario de emisiones y a plantear e implantar medidas para reducirlas. Se creó en el año 2010 y ya cuenta con más de 150 organizaciones adheridas ${ }^{26}$, la mayoría de las cuales han optado por acciones encaminadas a la reducción del consumo energético, con la disminución de costes asociada.

En el ámbito de la gobernanza cabe destacar la Comisión Interdepartamental del Cambio Climático creada el año 2007, la cual coordina la actuación del Gobierno en este ámbito con el objetivo de impulsar actuaciones de carácter transversal entre los diferentes departamentos para favorecer la adaptación al cambio climático y para disminuir las emisiones de los gases con efecto invernadero.

\footnotetext{
${ }^{26}$ La tipología de las organizaciones adheridas es muy variada. La empresa privada es la más representada, con un 70\%. Las entidades de la Administración Pública representan el 19\% del total, y las organizaciones sin ánimo de lucro, un $11 \%$. Desde un punto de vista sectorial, la posición más destacada la ocupan las consultorías e ingenierías, especialmente las dedicadas a cuestiones ambientales, junto con la industria.

<http://canviclimatic.gencat.cat/es/detalls/Noticies/Acte_lliurament_AAVV-00001> [Última consulta, 15 de mayo de 2018].
} 
También se han llevado a cabo actuaciones de incentivación por parte del Gobierno mediante el otorgamiento de ayudas que directa o indirectamente tienen implicaciones en materia de cambio climático ${ }^{27}$.

Pero también en el ámbito de la información y de participación pública se han desarrollado un gran número de actuaciones, como por ejemplo en la aprobación de la mayoría de los planes indicados anteriormente, se han incluido procesos de información y participación ${ }^{28}$.

Todo este conjunto de actuaciones ha permitido a Catalunya alcanzar una experiencia importante en la lucha contra el cambio climático. Así, fruto de la madurez y del compromiso de la política catalana se llega a la necesidad de disponer de una norma con rango de ley específica sobre cambio climático. Las razones que sustentan esta necesidad son ${ }^{29}$ : avanzar hacia un modelo económico de baja intensidad en carbono; adecuar la actuación de Catalunya en materia de cambio climático a la política climática de la Unión Europea; reafirmar el marco competencial autonómico; reforzar la coordinación dentro de la Administración catalana; y reforzar la planificación existente.

De este modo, en los últimos años en Catalunya se había discutido la conveniencia de disponer de una norma propia con rango de ley que sirviera de instrumento vertebrador de la política pública catalana de cambio climático. Si bien, como ya hemos visto, se han llevado a cabo diferentes tipos de actuaciones, disponer de una norma que cuente con el soporte necesario de las fuerzas políticas conlleva entrar en una dimensión de estabilidad y de seguridad jurídica más intensa y supone un compromiso más fuerte en la lucha contra el cambio climático ${ }^{30}$.

\footnotetext{
${ }^{27}$ Por ejemplo, el otorgamiento de ayudas para la implantación de medidas de ahorro y eficiencia energética en edificios o para el desarrollo de la movilidad eléctrica.

28 YÁBAR STERLING, A., "Mecanismos de consulta, participación y cooperación para una estrategia española de cambio climático", $M+A$, revista electrónica de medioambiente, 2006, núm. 2.

${ }^{29}$ En la memoria preliminar y en la memoria general del Anteproyecto de Ley se encuentra una descripción detallada de estas razones. Pero en la memoria de evaluación del impacto de las medidas propuestas del Anteproyecto de Ley de cambio climático se realiza una breve enumeración.

30 Tercer informe sobre el canvi climàtic a Catalunya, Institut d'Estudis Catalans y la Generalitat de Catalunya, Barcelona, 2016, p. 608.
} 


\section{LA INICIATIVA LEGISLATIVA CATALANA: LA LEY 16/2017, DE 1 DE AGOSTO, DEL CAMBIO CLIMÁTICO}

Ante el debate descrito anteriormente sobre la conveniencia de disponer una norma con rango de ley específica en materia de cambio climático, finalmente se tramitó esta iniciativa legislativa tan esperada. Se trata de una iniciativa legislativa, con un período de gestación dentro del ejecutivo autonómico especialmente $\operatorname{largo}^{31}$. No obstante, la aprobación de esta iniciativa ha supuesto la consolidación del trabajo realizado por Catalunya en materia de mitigación y adaptación en los últimos años y, especialmente, desde el año $2005^{32}$. El pasado 3 de agosto de 2017, se publicó en el Diario Oficial de la Generalitat de Catalunya la Ley 16/2017, de 1 de agosto, de cambio climático, que tiene por objeto "la regulación de las medidas encaminadas a la mitigación y la adaptación al cambio climático, la definición del modelo de gobernanza de la Administración pública con relación al cambio climático y el establecimiento de impuestos como instrumentos para actuar contra el cambio climático" (art. 1). Sin embargo, la aplicación de esta norma ha estado suspendida, como medida cautelar impuesta por el Tribunal Constitucional, a raíz del Recurso de inconstitucionalidad interpuesto ${ }^{33}$. Pero, recientemente el Tribunal Constitucional por Auto 36/2018,

31 Así, el 24 de mayo del 2012, el secretario de Medio Ambiente y Sostenibilidad firmó la propuesta de Acuerdo del Gobierno por la cual se aprobaba la memoria previa al inicio de la tramitación del Anteproyecto. Dos años más tarde, el Anteproyecto de Ley fue aprobado por el Gobierno el 6 de enero de 2016, a propuesta del consejero de Territorio y Sostenibilidad, y se autorizó la presentación al Parlamento. Vid. Boletín Oficial del Parlamento de Catalunya, de 25 de febrero de 2016.

32 Los autores de este informe consideran que este instrumento normativo está vivo y se trata de un motor de cambio. Tercer informe sobre el canvi climàtic a Catalunya, Institut d'Estudis Catalans y la Generalitat de Catalunya, Barcelona, 2016, p. 610

${ }^{33}$ El Pleno del Tribunal Constitucional, por providencia de 28 de noviembre actual, ha acordado admitir a trámite el Recurso de inconstitucionalidad núm.5334-2017, promovido por el presidente del Gobierno, contra los arts. 2.2. e), 4.e), 5, 6, 7, 8, 10, 11, 16.3, 19, 21.4, 24.3, 24.4, 40 a 50, 51 (inciso final del apartado 1 y letras a) y b) del apartado 3), 52.1, 52.3; las disposiciones adicionales primera, segunda, tercera y séptima; disposición transitoria tercera; y las disposiciones finales quinta y sexta. Esto conlleva la suspensión de la vigencia y aplicación de los preceptos impugnados desde la fecha de interposición del recurso para las partes del proceso y desde su publicación del correspondiente edicto en el Boletín Oficial del Estado, para los terceros. En el citado recurso se alega que la Ley catalana invade las competencias exclusivas del Estado en materia de bases y coordinación de la planificación general de la actividad económica, legislación básica sobre protección del medio ambiente y bases del régimen minero y energético (apartados 13, 23 y 25 del art. 149.1 de la CE), así como las competencias en materia de Hacienda general y de puertos de interés general (apartados 14 y 20 del art. 149.1 de la $C E$ ). Además, se considera que hay una dimensión de la Ley que permite considerarla como creadora de una estructura de Estado en la práctica, ajena a cualquier vinculación con las políticas y el marco jurídico del Estado, al prescindir por completo de las competencias exclusivas estatales. 
de 21 de marzo de 2018, ha acordado levantar la suspensión de los preceptos impugnados y solo la mantiene del artículo $19.4^{34}$.

El objeto y las finalidades que persigue esta norma le otorgan ineludiblemente un carácter sustancialmente ambiental. Esta norma consta de un Preámbulo, un Capítulo preliminar, seis capítulos, cincuenta y seis artículos, siete disposiciones adicionales, seis disposiciones transitorias y trece disposiciones finales.

En cualquier caso, cabe destacar que esta Ley va más allá de integrar las prescripciones que pueden ser exigibles por la legislación europea porque busca configurar un marco jurídico con vocación de estabilidad, con un objetivo principal y muy ambicioso como es facilitar la transición hacia una sociedad baja en carbono. En este sentido, se pretende que la norma sea un motor de cambio y que los postulados se integren en las políticas y en la planificación sectorial. Pero hay otras Comunidades Autónomas que han decidido seguir los pasos de Catalunya y utilizar la vía legislativa para dar respuesta a los problemas que plantea el cambio climático ${ }^{35}$. Este es el caso de Andalucía ${ }^{36}$, las Islas Baleares ${ }^{37}$ y la Región de Murcia ${ }^{38}$.

\subsection{Los objetivos de mitigación y de adaptación}

En les páginas anteriores se ha destacado que los objetivos del Acuerdo de París y los fijados por las iniciativas de la Unión Europea en materia de cambio climático también se deben entender como objetivos para las "subnational entities", como es el caso de Catalunya. Por consiguiente, debemos verificar que el contenido de esta Ley de cambio climático sea coherente con estos objetivos,

\footnotetext{
34 Art. 19.4. El Gobierno no concederá permisos de exploración para la obtención de gas y petróleo de esquisto por fracturación hidráulica horizontal (fracking), incluida la relacionada con la obtención de gas metano de capas de carbón con utilización de fracturación inducida.

35 Vid. NAVARRO RODRÍGUEZ, P., "Regulación autonómica de la lucha contra el cambio climático: entre Cataluña, País Vasco y Andalucía", El Cronista del Estado Social y Democrático de Derecho, núm. 75, 2018, pp. 22-27.

${ }^{36}$ Ley $8 / 2018$, de 8 de octubre, de medidas frente al cambio climático y para la transición hacia un nuevo modelo energético en Andalucía. Publicada en el BOE núm. 269, el 7 de noviembre de 2018.

${ }^{37}$ El Consejo de Gobierno de las Islas Baleares, a propuesta del Conseller de Territorio, Energia y Mobilidad, en la sesión del día 24 de agosto de 2018, adoptó el Acuerdo de aprobación del Proyecto de ley de cambio climático y transición energética.

38 La asociación Nueva Cultura por el Clima presentó, en junio de 2017, a la presidenta de la Asamblea y a los Grupos Parlamentarios una proposición de ley de Cambio Climático y Transición Energética de la Región de Murcia.
} 
si los incorpora como propios, si incrementa los valores que se proponen y si prevé fórmulas para la adaptación futura.

Los objetivos de la Ley respetan claramente las recomendaciones de las Naciones Unidas para hacer frente al cambio climático ${ }^{39}$. Los objetivos principales que incluye la Ley catalana son la regulación de las medidas encaminadas a la mitigación y la adaptación al cambio climático (art. 2) ${ }^{40}$.

Con esta Ley, como se afirma en su Preámbulo, se persiguen, básicamente, cinco finalidades: conseguir que Catalunya reduzca tanto las emisiones de GEI como la vulnerabilidad a los impactos del cambio climático, favorecer la transición hacia un modelo neutro en emisiones de GEI y, al mismo tiempo, transformar el modelo de producción y acceso a los recursos naturales y energéticos; reforzar y ampliar las estrategias y los planes que se han elaborado durante los últimos años en el ámbito del cambio climático; promover y garantizar la coordinación de todos los instrumentos de planificación sectorial relacionados con el cambio climático y la coordinación de todas las Administraciones públicas catalanas, así como fomentar la participación de la ciudadanía, de los agentes sociales y de los agentes económicos; convertirse en un país líder en la investigación y aplicación de nuevas tecnologías que contribuyan a la mitigación, así como a reducir la dependencia energética de Catalunya de recursos energéticos externos, a la descarbonización y a la desnuclearización; y hacer visible el papel de Catalunya en el mundo, tanto en los proyectos de cooperación como en la participación en los foros globales de debate sobre el cambio climático.

Pero, además, el propio articulado determina otras finalidades: a) Contribuir a la transición hacia una sociedad en la que el consumo de combustibles fósiles tienda a ser nulo, con un sistema energético descentralizado y con energías cien por cien renovables, fundamentalmente de proximidad, con el objetivo de

\footnotetext{
39 Véase la Estrategia europea de adaptación al cambio climático, el Paquete energía y clima objetivo 2020 y las Conclusiones del Consejo Europeo de objetivos de reducción del GEH para 2030.

40 El artículo 4 define los dos conceptos de adaptación y mitigación.

"Adaptación: Capacidad de ajuste de los sistemas naturales o humanos al cambio climático y a sus impactos para moderar los daños o aprovechar las oportunidades.

Mitigación: Intervención antropogénica que tiene por objetivo reducir las emisiones de gases de efecto invernadero o mejorar los sumideros".
} 
conseguir un modelo económico y energético no dependiente de los combustibles fósiles ni nucleares en 2050. b) Reducir la vulnerabilidad de la población, de los sectores socioeconómicos y de los ecosistemas terrestres y marinos ante los impactos adversos del cambio climático, así como crear y reforzar las capacidades nacionales de respuesta a estos impactos. c) Adaptar los sectores productivos e incorporar el análisis de la resiliencia al cambio climático en la planificación del territorio, las actividades, las infraestructuras y las edificaciones. d) Fomentar la educación, la investigación, el desarrollo y la transferencia de tecnología, y difundir el conocimiento en materia de adaptación y mitigación del cambio climático. e) Establecer mecanismos que provean información objetiva y evaluable sobre todos los aspectos relacionados con el cambio climático, su evolución temporal y sus impactos. f) Promover la participación ciudadana y la de los agentes económicos y sociales en la elaboración y evaluación de las políticas climáticas. g) Fijar los instrumentos de seguimiento de las emisiones de gases de efecto invernadero de Catalunya y para los diversos sectores, productos y servicios, durante todo su ciclo de vida. h) Definir los objetivos de reducción de emisiones de gases de efecto invernadero de Catalunya, establecer los correspondientes presupuestos de carbono globales y desagregados a nivel sectorial tomando como base su potencial de reducción. e) [Sic] Impulsar el cumplimiento de los compromisos internacionales con el cambio climático que vinculan a la Generalidad y la cuota alícuota correspondiente de los tratados internacionales suscritos por el Estado español, de acuerdo con los criterios de repartimiento de esfuerzos que tengan establecidos ${ }^{41}$.

Todas estas finalidades responden al objetivo último de reducir las emisiones de GEI y la vulnerabilidad del país ante los efectos del cambio climático. Por tanto, son las herramientas para conseguir los objetivos principales.

En cuanto a las diversas iniciativas legislativas de otras Comunidades Autónomas, el objeto de cada una de ellas es la regulación de las medidas encaminadas a la mitigación y la adaptación al cambio climático. No obstante, existen algunas diferencias importantes en la concreción de las finalidades de

\footnotetext{
${ }^{41}$ Art. 2.2.
} 
estas leyes. De este modo, tanto la Ley catalana, el Proyecto de Ley de las Islas Baleares y la reciente Ley andaluza incorporan el concepto de la transición a un modelo energético sostenible $\mathrm{o}$, como indica el legislador catalán, hacia una economía neutra en emisiones de gases de efecto invernadero, competitiva y eficiente en el uso de los recursos. Sin embargo, Murcia, tan solo menciona en el objeto de la ley que "se establecen medidas para la transición a una economía competitiva, innovadora, sostenible, base de una sociedad inclusiva y cohesionada territorialmente".

\subsection{La mitigación del cambio climático:}

En cuanto a la mitigación del cambio climático, en el capítulo I de la Ley catalana, se establece la obligación por parte del Gobierno de presentar al Parlamento los objetivos de reducción de emisiones de GEl y de los contaminantes del aire para los periodos de cumplimiento (art. 5). Además, cabe destacar el compromiso del Gobierno en aprobar el Marco estratégico de referencia de mitigación, en el plazo de un año a contar desde la fecha de publicación de la Ley, a propuesta de la Comisión Interdepartamental del Cambio Climático y con la participación de los entes locales y los demás actores implicados. Como se determina en el apartado segundo del artículo 6, esto es el instrumento que debe recoger los objetivos de emisiones de gases con efecto invernadero y de los contaminantes del aire para los periodos considerados, así como una propuesta de las medidas necesarias para alcanzarlos de manera planificada y estableciendo indicadores cuantitativos anuales del impacto de las acciones. Se concreta que dicho Marco estratégico es de obligado cumplimiento para los actores implicados. Pero también regula dos mecanismos más de planificación y seguimiento para la integración de los objetivos de la ley en las políticas sectoriales: los presupuestos de carbono (art. 7) y el inventario de emisiones a la atmósfera y sumideros de $\mathrm{CO}_{2}$ de Catalunya (art. 8).

4.2.1. Los objetivos de reducción de emisiones de gases de efecto invernadero El artículo 5 establece que el Gobierno debe presentar al Parlamento los objetivos de reducción de emisiones de gases de efecto invernadero y de los 
contaminantes del aire para los períodos de cumplimiento que establezcan la Unión Europea y la Organización Mundial de la Salud. De acuerdo con este precepto: "El objetivo para cada período de cumplimiento se fija tomando como referencia la reducción acordada para el conjunto de la Unión Europea y los criterios de repartimiento de esfuerzos que la Unión Europea fija para los estados miembros, incorporando siempre las actualizaciones que la Conferencia de las Partes (COP) de la Convención marco de las Naciones Unidas sobre el Cambio Climático establezca".

Pero es la disposición adicional primera donde se establecen los objetivos de reducción de emisiones de GEI. Así, de acuerdo con este articulado: "1. El objetivo de reducción de emisiones de gases de efecto invernadero para el año 2030 es del $40 \%$ respecto al año base (1990), del $65 \%$ para 2040 y del $100 \%$ para 2050. 2. El objetivo de reducción de los óxidos de nitrógeno para el año 2020 es del 35\%, y el de reducción de las partículas en suspensión de menos de 10 micras, del 30\%. 3. Los objetivos de reducción de gases de efecto invernadero para las energías renovables ${ }^{42}$ en la producción energética y para la eficiencia energética son del $100 \%$ con el horizonte de un modelo neutro en emisiones de carbono para 2050".

En primer lugar, debemos analizar la adecuación de los objetivos de reducción de emisiones de GEI a los parámetros establecidos en el ámbito de la Unión Europea. En este contexto, los objetivos de reducción de emisiones de gases de efecto invernadero establecidos se ajustan a los parámetros establecidos en el ámbito de la Unión Europea. Para el período 2013-2020, el Paquete Europeo de Energía y Cambio Climático, establece que las emisiones del conjunto de la Unión Europea se reducirán en un $20 \%$ en relación con los niveles de 1990 . El esfuerzo para conseguir estas reducciones se reparte en dos bloques: por un

\footnotetext{
42 Sobre energías renovables y cambio climático véase, entre otros, ALENZA GARCíA, J. F., (dir.), La regulación de las energías renovables ante el cambio climático, Cizur Menor, Thomson Reuters Aranzadi, 2015; ALENZA GARCÍA, J. F., "¿Hacia un marco jurídico común de energías renovables y cambio climático?", en RIVERO ORTEGA, R., RASTROLLO SUÁREZ, J. J. (coords.), Actas del XI Coloquio Hispano-Portugués de Derecho Administrativo, Salamanca, Universidad de Salamanca, 2014, pp. 137-145. GONZÁLEZ RíOS, I., ÁVILA RODRÍGUEZ, C. M., (coords.), Estudios sobre la normativa reguladora de la eficiencia energética. Especial referencia a su incidencia en las Administraciones públicas, Madrid, ThomsonReuters-Aranzadi, 2016. GALÁN VIOQUE, R., GONZÁLEZ RíOS, I., Derecho de las energías renovables y la eficiencia energética en el horizonte 2020, Pamplona, Aranzadi, 2017.
} 
lado, en relación con las emisiones de $\mathrm{CO}_{2}$ de los sectores más intensivos en el uso de la energía, sometidos al comercio europeo de derechos de emisión, el objetivo global a nivel europeo es alcanzar en 2020 una reducción de sus emisiones del $21 \%$ en relación con sus niveles de 2005 . Por el otro, el resto de emisiones, para las que se incluyen en la Decisión 406/2009/CE del Parlamento Europeo y del Consejo de 23 de abril de 2009, sobre el esfuerzo de los Estados miembros para reducir sus emisiones de $\mathrm{GEI}$, con el fin de cumplir los compromisos adquiridos por la Comunidad hasta 2020 —energía (quema de combustible y emisiones fugitivas de combustibles), procesos industriales, utilización de disolventes y otros productos, agricultura y residuos-, el objetivo de reducción en las emisiones de GEl es del 10\% en relación con los niveles del año 2005, objetivo que se reparte entre los diferentes Estados miembros a través de la mencionada Decisión. De acuerdo con esta decisión, a España le corresponde una reducción del 10\%. Dentro de este mismo período 2013-2020, la Unión Europea se ha comprometido a aplicar una segunda fase del Protocolo de Kyoto y a reducir las emisiones de gases de efecto invernadero en un $20 \%$ en relación con el año 1990.

En cuanto al período 2021-2030, los objetivos de reducción de emisiones se recogen en las Conclusiones del Consejo Europeo de octubre de 2014, en que se aprobó el Marco de Políticas de Energía y Cambio Climático 2021-2030. Concretamente, se establece un objetivo vinculante para la Unión Europea en 2030, como mínimo, un 40\% menos de emisiones de GEl en comparación con 1990. Este compromiso se convirtió en la base del compromiso internacional de la Unión Europea en el marco del Acuerdo de París sobre Cambio Climático y la deben asumir colectivamente todos los Estados miembros.

En relación con los objetivos de reducción de emisiones fijados con el horizonte de 2050, la Unión Europea se marca un objetivo de reducción de emisiones para el conjunto de su territorio del 80 al 95\%, comparado con los niveles de $1990^{43}$.

\footnotetext{
${ }^{43}$ Estos objetivos de reducción de emisiones establecidos a nivel internacional y europeo, hasta el momento actual, no han sido objeto de concreción por parte de España en ninguna legislación básica aprobada en materia de cambio climático. La única Ley aprobada en este ámbito por el Estado es la Ley 1/2005, de 9 de marzo, reguladora del régimen del comercio de derechos de emisión de gases de efecto invernadero, que se limita a regular el comercio de derechos de emisión.
} 
Ante este contexto, hay que destacar que los objetivos de reducción de emisiones de GEl establecidos en la Ley catalana son plenamente respetuosos con los compromisos asumidos por España como Estado signatario de la Convención Marco de Naciones Unidas sobre Cambio Climático y como miembro de la Unión Europea. Efectivamente, el objetivo fijado para el año 2030 coincide con el objetivo vinculante fijado para la Unión Europea (reducción del 40\%), y el objetivo establecido para el año 2050 se sitúa en la línea de los fijados por la Unión Europea, incluso va más allá y establece el 100\%.

Esta opción de establecer objetivos autonómicos vinculantes de reducción de emisiones ha sido seguida por todas las Comunidades Autónomas que han adoptado iniciativas regulatorias en materia de cambio climático y también por otros entes subestatales en el derecho comparado ${ }^{44}$.

\subsection{La adaptación al cambio climático: marco estratégico de referencia e instrumentos de planificación y programación}

La adaptación al cambio climático, se prevé en el capítulo II, con el objetivo que Catalunya se convierta en menos vulnerable a los impactos del cambio climático a través de los instrumentos de planificación y programación que se establecen en esta ley. Con esta finalidad se establece la obligación de elaborar el marco estratégico de referencia de adaptación (art. 10).

El Departamento que tiene competencias en materia de cambio climático debe elaborar, junto con otros departamentos y con la participación de los actores implicados, con la previa presentación a la Mesa Social del Cambio Climático, el marco estratégico de referencia, el cual debe contemplar: la evaluación de los impactos; la identificación de los sistemas naturales, de los territorios y de los sectores socioeconómicos más vulnerables; y la propuesta de las medidas de adaptación necesarias para reducir la vulnerabilidad.

La Generalitat se obliga a elaborar este marco estratégico para establecer una serie de medidas concretas que deberán realizarse para reducir la vulnerabilidad

${ }^{44}$ En Europa existen ejemplos de normativas aprobadas por entes subestatales que incluyen objetivos vinculantes de reducción de emisiones de gases de efecto invernadero. Este es el caso de la Climate Change (Scotland) Act, aprobada por el Parlamento escocés per unanimidad, el año 2009. 
ante los impactos del cambio climático. Esto es el resultado del compromiso de la Generalitat de cumplir con la recomendación que realiza la Unión Europea en el Libro Verde de Adaptación al Cambio Climático, sobre que todas las organizaciones administrativas europeas redacten sus planes de adaptación.

No obstante, cabe destacar que este compromiso ya se plasmó en el marco estratégico de referencia vigente para el horizonte 2013-2020 que se aprobó por el Acuerdo de Gobierno de 13 de noviembre de 2012, la llamada ESCACC. Por tanto, mediante una norma con rango de ley se ha querido dotar de mayor fuerza jurídica a ese compromiso de la Generalitat. La ESCACC se ha convertido, conforme a la disposición adicional tercera de la Ley, en el elemento de planificación de las políticas de adaptación a partir de la que los departamentos de la Generalitat, deben desarrollar los planes de acción sectoriales correspondientes. Este reconocimiento de la Estrategia por parte de la Ley es muy importante porque refuerza a la misma estrategia y facilita su aplicación.

También se establece que todos los departamentos de la Generalitat deben integrar en su planificación y programación sectorial los objetivos referentes a la reducción de la vulnerabilidad a los impactos del cambio climático que recoge el Marco estratégico de referencia de adaptación. Concretamente, los instrumentos de planificación y programación, deben incorporar: a) la evaluación sistemática de los impactos observados y previstos del cambio climático sobre los sectores socioeconómicos, los sistemas productivos, los sistemas naturales y los territorios más vulnerables; b) el conocimiento disponible en materia de proyecciones climáticas en Catalunya para varios horizontes temporales; c) el establecimiento de las medidas de respuesta viables económica, social y ambientalmente que deben adoptar las instituciones públicas y los agentes privados con el objetivo de adaptarse a los impactos del cambio climático; d) un sistema de seguimiento de los efectos de la planificación en materia de adaptación.

Otro de los objetivos que persigue la adaptación es el de contribuir a introducir los cambios necesarios en los sistemas económicos, sociales y ambientales que garanticen su funcionalidad en las nuevas condiciones climáticas. Para lograr estos objetivos, el legislador catalán potencia la coordinación intersectorial. Así, en el capítulo III (políticas sectoriales), se trata de integrar en la planificación, la 
ejecución y el control de las políticas sectoriales del Gobierno las medidas adecuadas para reducir la vulnerabilidad al cambio climático. De este modo, se introducen una serie de medidas de adaptación y mitigación del cambio climático en los siguientes ámbitos: la agricultura, la ganadería, la pesca, la acuicultura, el agua, la biodiversidad, los bosques, la gestión forestal, la energía, la industria, los servicios, el comercio, las infraestructuras, los residuos, la salud, los transportes, la movilidad, el turismo, la formación profesional, las universidades, la investigación, el urbanismo y la vivienda. Aunque casi todas las medidas recogidas tienen un carácter programático o inspirador, también hay algún ámbito que prevé una normativa sectorial. Dentro de este último supuesto, cabe reseñar el ámbito de los residuos ${ }^{45}$.

La Ley catalana otorga un peso relevante a los planes y programas aprobados por las Administraciones públicas catalanas y al papel que ejercen y pueden ejercer en la valoración y la incorporación de los aspectos relacionados con el cambio climático. Este sistema, a través de una norma con rango de ley, otorga una mayor seguridad jurídica y permite la formulación de políticas sectoriales coherentes con el cambio climático ${ }^{46}$.

Esta obligación de implementar medidas de adaptación al cambio climático a través de los instrumentos de planificación y programación, se puede observar también en todas las otras iniciativas legislativas autonómicas sobre el cambio climático.

Por un lado, el legislador andaluz al regular el Plan Andaluz de Acción por el Clima, establece la obligación que en su formulación se integren acciones de adaptación del cambio climático. A estos efectos, regula el llamado Programa de Adaptación, el cual tiene por objeto reducir los riesgos económicos, ambientales y sociales derivados del cambio climático mediante la incorporación de medidas de adaptación en los instrumentos de planificación autonómica y local. Además, dedica un capítulo específico a la integración de la adaptación al cambio climático en los instrumentos de planificación y diseña dos instrumentos de

\footnotetext{
45 Art. 22.

46 Tercer informe sobre el canvi climàtic a Catalunya, Institut d'Estudis Catalans y la Generalitat de Catalunya, Barcelona, 2016, p. 612.
} 
referencia para la planificación: los Escenarios Climáticos de Andalucía y el Inventario Andaluz de Emisiones de Gases de Efecto Invernadero.

En el caso del Proyecto de ley de las Islas Baleares también se ha optado por la implementación de medidas de adaptación a través de la planificación. Así, se regula el llamado Plan de Transición Energética y Cambio Climático, como la principal herramienta planificadora, cuyas determinaciones serán vinculantes para el Plan Director Sectorial Energético y para otros tipos de planes. Este plan debe contener entre sus apartados, el marco estratégico de adaptación (art. 11). La proposición de Ley de la Región de Murcia prevé -en el plazo de dos años desde la entrada en vigor de la Ley- la aprobación de la Estrategia de Cambio climático de la Región de Murcia, como instrumento general de planificación para la lucha contra el cambio climático en la Comunidad Autónoma, con la consideración de estrategia territorial. La Ley fija su contenido, procedimiento de aprobación y seguimiento y establece que incluirá los programas de Mitigación, Adaptación y Formación y Comunicación, con el alcance y contenido que prevé la Ley. Establece como instrumentos de referencia para la planificación los mapas Climáticos de la Región de Murcia y el Inventario de Emisiones de Gases de Efecto Invernadero de la Región de Murcia (art. 12) e incluye otros instrumentos de planificación climática: los Planes Municipales de Cambio Climático (art. 16), prevé la integración de los objetivos de reducción de emisiones y adaptación al cambio climático en la planificación sectorial con incidencia sobre el cambio climático (art. 17) y crea las Zonas Especiales de Adaptación al Cambio climático (ZEACC). Se trata de áreas en las que la vulnerabilidad al cambio climático resulta de especial intensidad. Estas áreas las declarará el Consejo de Gobierno a propuesta del Consejo Interdepartamental de Cambio Climático y lo hará mediante Decreto.

\subsection{Conflicto competencial: la impugnación de la Ley de cambio climático ante el Tribunal Constitucional}

Los preceptos de la Ley 16/2017, del 1 de agosto, del cambio climático comentados en los apartados anteriores (arts. 2.2. e, 4, 5, 6, 7, 9, 10 y 11) han 
sido impugnados en el marco del Recurso de inconstitucionalidad presentado contra esta Ley por el presidente del Gobierno.

El Abogado del Estado argumenta que los preceptos impugnados ponen en funcionamiento un régimen jurídico propio autonómico que transpone la normativa europea e internacional, sin tener en cuenta la normativa básica estatal, que "en este ámbito el Tribunal Constitucional considera de competencia exclusiva estatal, en cuanto que su transversalidad demanda esa unificación territorial de la regulación al amparo de los títulos competenciales de las reglas $13^{\mathrm{a}}$ y $23^{\mathrm{a}}$ del art. 149.1 de la CE".

También afirma que la regulación de estos preceptos excede de lo que es una mera potestad o competencia de ejecución en materia de medio ambiente, dado que diseñan toda una política de medio ambiente en relación con el cambio climático.

Asimismo, se alega una falta de consideración por parte del legislador autonómico del marco normativo estatal en regular los objetivos de reducción de las emisiones de los gases de efecto invernadero. También, inexistencia de una remisión a la normativa estatal y falta de voluntad de adecuación a una política plasmada en una normativa estatal a la que se deberían haber remitido o referido en tanto que consideraran su propia como mera ejecución de esta, no directamente de la europea e internacional. Así, se afirma que

"En modo alguno subyace a ellos la voluntad de adecuación a una política plasmada en una normativa estatal a la que hubieran de haberse remitido o referido en tanto que consideraran la suya propia como mera ejecución de ésta, no directamente de la europea e internacional, como se ve que trata de arrogarse con la remisión directa y cita sólo de las normas internacionales que supuestamente estarían aplicando o transponiendo en su territorio, sin contemplación de la de carácter unitario y transversal del Estado".

Además, el Abogado del Estado también afirma que la lucha contra el cambio climático tiene carácter transversal, motivo por el cual, considera que no es posible establecer una planificación de los diferentes sectores de la economía y de los objetivos a alcanzar en cada uno de ellos, como si estas decisiones constituyeran exclusivamente una norma adicional de protección. Por este motivo, 
“[...] tampoco resulta posible que las Comunidades Autónomas territorialicen los objetivos de emisiones asignados a cada una de ellas como si de Estados miembros de la Unión Europea se tratara, y establezcan su propia distribución de objetivos entre los distintos sectores, determinando de manera muy relevante el contenido de las distintas políticas sectoriales, con total independencia de las decisiones adoptadas al respecto por el Estado".

En definitiva, se alega una vulneración de las competencias básicas estatales (ex art. 149.1, apartados 13, 25 y $23 \mathrm{CE}$ ) en la medida en que se hace una configuración de los instrumentos esenciales de mitigación del cambio climático completamente al margen de la regulación establecida por el Estado,

“ [...] de modo que únicamente parte el legislador autonómico de la idea de que a él le corresponde "Impulsar el cumplimiento de los compromisos internacionales con el cambio climático que vinculan a la Generalidad y la cuota alícuota correspondiente de los tratados internacionales suscritos por el Estado español, de acuerdo con los criterios de repartimiento de esfuerzos que tengan establecidos".

“[...] Por lo demás, en nada tiene en consideración el legislador autonómico el marco normativo estatal al regular los objetivos de reducción de emisiones de gases de efecto invernadero, el marco estratégico de referencia de mitigación, los presupuestos de carbono, el inventario de emisiones a la atmósfera y de sumideros de $\mathrm{CO}_{2}$ de Cataluña, el arco estratégico de referencia de adaptación o los instrumentos de planificación y programación".

Así, se argumenta que las competencias ambientales de la Comunidad Autónoma, como competencias compartidas, deben respetar la competencia estatal otorgada por el artículo 149.1.23 CE:

"Siendo aquí el alcance de la competencia compartida, en el establecimiento de normas adicionales de protección, pues, y parafraseando la STC 14/2004, de 13 de febrero, "respecto al 'medio ambiente' hemos declarado que "tal y como ha sido descrito, es un concepto nacido para reconducir a la unidad los diversos componentes de una realidad en peligro. Si este no se hubiera presentado resultaría inimaginable su aparición por meras razones teóricas, científicas o filosóficas, ni por tanto jurídicas. Los factores desencadenantes han sido la erosión del suelo, su deforestación y desertización, la contaminación de las aguas marítimas, fluviales y 
subálveas, así como de la atmósfera por el efecto pernicioso de humos, emanaciones, vertidos y residuos, la extinción de especies enteras o la degeneración de otras y la degradación de la riqueza agrícola, forestal, pecuaria o piscícola, la contaminación acústica y tantas otras manifestaciones" (STC 102/1995, de 26 de junio, FJ 7)" (FJ 10).

En la misma línea, el Consejo de Estado, en su Dictamen 904/2017, de 2 de noviembre ${ }^{47}$, también considera que Catalunya no puede, en su Ley, disciplinar un régimen singularizado en materia de lucha contra el cambio climático en su territorio, con la definición de objetivos propios de reducción de emisiones de gases de efecto invernadero e instrumentando las herramientas necesarias para alcanzarlos con total desvinculación de las reglas que resulten de la planificación realizada por el Estado y de la aplicación de su normativa básica. Se afirma en este Dictamen, en relación con el tema que nos ocupa, que:

"La puesta en marcha del mercado de emisiones exige, por su parte, establecer tanto las bases que rigen su funcionamiento, como adoptar una serie de medidas singulares de ejecución que garanticen la existencia de unos criterios homogéneos para el reparto de derechos en todo el territorio nacional, de manera que el número de derechos que se asigna sea coherente con los compromisos internacionales en materia de emisiones de gases de efecto invernadero asumidos por España y que las previsiones de emisión para todos los sectores incluidos y la valoración de la contribución de las instalaciones al total de las emisiones nacionales y de las posibilidades técnicas y económicas de reducción de emisiones de las instalaciones en todos los sectores se realicen de forma equitativa.

[...] es el Estado el que debe acometer la regulación necesaria para dar cumplimiento a los compromisos internacionales asumidos por España en materia de reducción de gases de efecto invernadero, sin que quepa admitir la posibilidad de que las comunidades autónomas, actuando en ejercicio de sus competencias en materia de protección del medio ambiente, lleven a cabo una regulación propia paralela a aquella, dando lugar a una territorialización de los objetivos asignados a cada una de ellas y

47 Emitido con carácter previo a la interposición del Recurso de inconstitucionalidad contra la Ley catalana de cambio climático. 
estableciendo su propia distribución de objetivos entre los distintos sectores afectados, al margen de lo que el Estado decida".

Así, considera que: "[...] los artículos de la Ley catalana antes mencionados disciplinan un régimen singularizado para el territorio de Cataluña en materia de lucha contra el cambio climático, definiendo sus propios objetivos de reducción de emisiones de gases de efecto invernadero e instrumentando las herramientas necesarias para alcanzarlos con total desvinculación de las reglas que resulten de la planificación realizada por el Estado y de la aplicación de su normativa básica".

En consecuencia, concluye que "existen fundamentos jurídicos suficientes para proceder a la impugnación pretendida, que ha de alcanzar, igualmente, a las disposiciones adicionales primera, segunda y tercera, dada la conexión que las medidas en ellas establecidas guardan con el régimen de mitigación y adaptación al cambio climático que establecen los preceptos examinados".

Sobre estos argumentos del Abogado del Estado y del Consejo de Estado, en primer lugar, consideramos necesario destacar la jurisprudencia del Tribunal Constitucional sobre la aplicación del Derecho de la Unión Europea. El Alto Tribunal, de forma reiterada, ha establecido que la incorporación al derecho interno de la normativa europea y su ejecución deben seguir los criterios constitucionales y estatutarios de reparto de competencias establecidos a nivel interno, que no resultan alterados debido a que el ejercicio de una competencia se produzca en ejecución del Derecho de la Unión Europea ${ }^{48}$. Así, el Tribunal Constitucional manifiesta que:

"[...] el hecho de que las Directivas europeas tengan como finalidad la de homogeneizar, aproximar o armonizar los distintos ordenamientos y que sean de obligado cumplimiento por todas las autoridades o instituciones, centrales y descentralizadas, de los Estados miembros y que, incluso, puedan tener un efecto directo, no significa que las normas estatales que las adapten a nuestro ordenamiento deban ser consideradas necesariamente "básicas". Aquellas disposiciones del Derecho comunitario vinculan, desde luego, a las Comunidades Autónomas, pero por su propia fuerza normativa

${ }^{48}$ SSTC 102/1995, de 26 de junio; 147/1998, de 2 de julio; 20/2014, de 10 de febrero; o 141/2016, de 21 de julio. 
y no por la que le atribuya su traslación al Derecho interno como normas básicas. Y si bien esa necesaria adaptación puede llevar en ciertos casos a dictar normas internas de contenido prácticamente uniforme para todo el territorio de la Nación, tal regulación sólo corresponde hacerla al Estado mediante normas de carácter básico en la medida en que lo permitan la Constitución y los Estatutos de Autonomía"49.

Por tanto, no existe un título competencial específico en favor del Estado para la ejecución del Derecho de la Unión Europea y el hecho de tener que cumplir los parámetros fijados por la Unión Europea en materia de cambio climático no prejuzga si el ejercicio de las competencias que supongan desarrollo normativo o ejecución de normas u obligaciones impuestas por la Unión Europea corresponde al Estado o a las Comunidades Autónomas. En consecuencia, la problemática competencial se debe resolver de conformidad con las reglas internas de distribución de competencias en la materia que resulte afectada - en este caso, la protección del medio ambiente-.

Catalunya, puede desarrollar y ejecutar el Derecho de la Unión Europea de acuerdo con sus competencias, y adoptar una política propia y un marco legal en materia de cambio climático adaptado a su realidad política, social, económica y ambiental para garantizar el cumplimiento en su ámbito territorial de los objetivos de reducción de emisiones establecidos por la Unión Europea. Además, en un contexto de ausencia de norma básica estatal de cambio climático, está acción de Catalunya, todavía resulta más imprescindible. La falta de regulación estatal no puede impedir el ejercicio de las competencias autonómicas para desarrollar plenamente en su territorio todos los objetivos fijados por la Unión Europea en materia de cambio climático.

Por tanto, Catalunya puede dictar legislación de desarrollo directamente a partir del Derecho de la Unión Europea, sin perjuicio de que el Estado pueda aprobar legislación básica en la materia ${ }^{50}$.

\footnotetext{
49 STC 102/1995, de 26 de junio, FJ 14.

50 En este sentido se ha pronunciado, en materia de contratación pública, un Acuerdo de la Subcomisión de Seguimiento Normativo, Prevención y Solución de Conflictos de la Comisión Bilateral Generalitat-Estado en relación con el Decreto ley 3/2016, de 31 de mayo, de medidas urgentes en materia de contratación pública. En este Acuerdo se adoptaron una serie de compromisos y criterios interpretativos, entre ellos, y a los efectos que aquí nos interesan, destacamos los siguientes: a) Ambas partes entienden que, tal como quedó expuesto en el Preámbulo del Decreto Ley 3/2016, "El artículo 189.3 del Estatuto de Autonomía de Cataluña
} 
En cuanto al título competencial que sirve de fundamento al establecimiento de objetivos de reducción de emisiones y los instrumentos necesarios en el ámbito de la mitigación y la adaptación, cabe destacar la protección del medio ambiente. Sobre la distribución de competencias en materia de medio ambiente, el articulo 149.1.23 establece que "el Estado tiene competencia exclusiva: [...]: Legislación básica sobre protección del medio ambiente, sin perjuicio de las facultades delas Comunidades Autónomas para el establecimiento de normas adicionales de protección". Por su parte, el artículo 144 del Estatuto de Autonomía de Catalunya prescribe que "Corresponde a la Generalitat la competencia compartida en materia de medio ambiente y la competencia para el establecimiento de normas adicionales de protección".

En cuanto a la naturaleza y el alcance de esta materia competencial, el Tribunal Constitucional ha interpretado: "La configuración de la competencia en esta materia, que comparten el Estado y las Comunidades Autónomas, contiene un primer elemento objetivo, estático, el medio ambiente como tal, y otro dinámico funcional, que es su protección, soporte de las potestades a su servicio. Ambos aspectos de tal actividad pública hacen surgir el componente medioambiente de las demás políticas sectoriales" 51 .

Pero la jurisprudencia constitucional ha insistido en que las bases son un común denominador (SSTC 48 y 49/1988, de 22 de marzo; 197/1996, de 28 de noviembre, entre otras). Así, el Tribunal Constitucional ha advertido que las bases de la ordenación de una materia no pueden llegar a presentar un grado

dispone que, en caso de que la UE establezca una legislación que sustituya a la normativa básica del Estado, la Generalitat puede adoptar la legislación de desarrollo a partir de las normas europeas". Todo ello, sin perjuicio de la competencia del Estado para adoptar la legislación básica sobre contratos y concesiones administrativas, en los términos que estableció la STC 31/2010 (FJ 123).

b) En la actualidad se encuentran en tramitación en las Cortes Generales y en el Parlamento de Cataluña sendos proyectos de Ley que inciden en la contratación en el sector público a efectos de incorporar al Ordenamiento Jurídico la normativa comunitaria pendiente de transposición. En este contexto, ambas partes entienden que, a fin de garantizar la adecuada articulación entre las competencias del Estado y de la Generalidad de Catalunya, corresponde a la Generalidad de Cataluña aplicar la normativa básica estatal que adopte y promover la adaptación de la legislación de desarrollo autonómico de esta normativa básica estatal. Se lo corresponde asimismo el desarrollo de la legislación básica de contratos públicos.

El razonamiento utilizado en materia de contratación pública en este puede ser plenamente extrapolable al ámbito del cambio climático.

51 STC 202/1995, de 26 de junio, FJ 4. 
de determinación que vacíe de contenido la competencia autonómica (SSTC 1/1982, de 28 de enero; 125/1984, de 20 de diciembre, entre otras).

También en la citada STC 102/1995, el Tribunal Constitucional ya subrayó que la legislación básica cumple una función garantía de un estándar mínimo de protección, de tal manera que no excluye que las Comunidades Autónomas pueden adoptar un grado superior de protección. En este sentido, establece que: "Lo básico, como propio de la competencia estatal en esta materia, cumple más bien una función de ordenación mediante mínimos que han de respetarse en todo caso, pero que pueden permitir que las Comunidades Autónomas con competencia en la materia establezcan niveles de protección más altos"52.

Por lo tanto, esta competencia autonómica para dictar normas adicionales de protección del medio ambiente es clave en esta materia, dado que permite, como ha establecido la jurisprudencia constitucional, que las Comunidades Autónomas puedan establecer niveles de protección más altos ${ }^{53}$. Así, los niveles de protección de la normativa estatal pueden ser ampliados y mejorados por la normativa autonómica, únicamente resultaría constitucionalmente improcedente la restricción o disminución esta protección ambiental ${ }^{54}$.

En efecto, el título competencial de protección del medio ambiente es el prevalente para regular la materia que aquí nos ocupa. Así lo destaca el propio Estado en la única norma con rango de ley elaborada en materia de cambio climático aprobada hasta ahora: la Ley $1 / 2005$, de 9 de marzo, reguladora del régimen del comercio de derechos de emisión de gases de efecto invernadero 55 . A pesar de que para la aprobación de esta Ley se utiliza un doble fundamento competencial —el art. 149.1.23 CE y el art. 149.1.13 CE-, en la Exposición de Motivos se deja bien claro que esta Ley es una norma sustancialmente medioambiental. Así,

\footnotetext{
52 FJ 9.

53 STC 170/1989, de 19 de octubre.

${ }^{54}$ Así lo ha establecido el Tribunal Constitucional de forma reiterada (por ejemplo, en las SSTC 170/1989, de 19 de octubre, 90/2000, de 30 de marzo, y 7/2012, de 18 de enero).

55 Véase, entre otros, ALVAREZ FERNÁNDEZ, M., "Las políticas públicas frente al cambio climático: el Plan Nacional de Asignación de Derechos de Emisión de Gases de Efecto Invernadero", Noticias de la Unión Europea, 2007, núm. 271-272, pp. 59-80; SANZ RUBIALES, Í., (coord.), Cambio climático y Unión Europea, Valencia, Tirant lo Blanch, 2014.
} 
"[...] tanto su objetivo -contribuir a la reducción de las emisiones antropogénicas de efecto invernadero- como su origen -los compromisos asumidos con arreglo al Protocolo de Kioto y la propia directiva-, le otorgan ineludiblemente este carácter.

"En consecuencia, corresponde invocar el artículo 149.1.23. " de la Constitución Española que reserva al Estado la competencia exclusiva para dictar la legislación básica sobre protección del medio ambiente, sin perjuicio de las facultades de las Comunidades Autónomas de establecer normas adicionales de protección.

En virtud de todo lo anterior, se han regulado con carácter de legislación básica en materia de protección del medio ambiente las autorizaciones de emisión, las obligaciones de seguimiento de las emisiones, de remisión de información y la verificación, salvaguardando las competencias autonómicas de dictar normas de desarrollo que establezcan un nivel de protección superior y, evidentemente, sus competencias de ejecución o gestión en materia de medio ambiente".

Es evidente, por lo tanto, el carácter sustancialmente ambiental de la regulación sobre las emisiones y la posibilidad de que las Comunidades Autónomas puedan dictar normas que establezcan un nivel de protección superior.

En conclusión, el establecimiento de objetivos mínimos de reducción de emisiones y la regulación de los instrumentos de mitigación y adaptación, por su naturaleza, constituiría una norma de carácter sustancialmente ambiental y, en consecuencia, justificada en las competencias autonómicas recogidas en el artículo 144 del Estatuto de Autonomía de Catalunya.

Por lo tanto, consideramos que la Ley catalana en la regulación que efectúa de la reducción de emisiones y, en especial, en el establecimiento de objetivos mínimos de reducción de emisiones que se efectúan y los instrumentos de mitigación y adaptación comentados anteriormente, es plenamente respetuosa con la actual normativa básica estatal. En este sentido, hay que partir de que, a nivel estatal únicamente se ha regulado, mediante la Ley 1/2005, el mercado de emisiones, pero no existe una Ley General de cambio climático y transición energética. Por lo tanto, desde un punto de vista competencial, no resultan cuestionables las previsiones de la Ley catalana que desarrollan el Derecho de la Unión Europea y pretenden hacer efectivos los compromisos establecidos 
tanto a nivel internacional como europeo. De este modo, la norma pretende cubrir un vacío legal y toma como referencia directamente los objetivos establecidos por la Unión Europea, en la medida en que en este punto no existe normativa básica estatal. Así pues, no se vulnera la normativa básica estatal porque no existe.

Por otra parte, hay que tener en cuenta que la Ley $34 / 2007$, de 15 de noviembre, de calidad del aire y protección de la atmósfera, a su artículo 5.2, prevé expresamente que las Comunidades Autónomas, en el ejercicio de sus competencias, podrán establecer objetivos de calidad del aire y valores límites de emisión más estrictos que los establecidos por la Administración General del Estado de acuerdo con el artículo 5.1. Esta posibilidad también está expresamente recogida en el artículo 7.2 del Real Decreto Legislativo 1/2016, de 16 de diciembre, por el que se aprueba el texto refundido de la Ley de Prevención y Control Integrados de la Contaminación.

Así, en la medida en que la propia normativa básica reconoce de forma expresa que se pueden fijar valores límites de emisión más estrictos, también será posible fijar objetivos de reducción de emisiones de gases de efecto invernadero más estrictos que los que pueda establecer el estado, respetando siempre los mínimos marcados por la legislación básica estatal, la normativa de la Unión Europea y los compromisos internacionales asumidos por España.

En este sentido, la jurisprudencia del Tribunal Constitucional considera que las bases o normas básicas son nociones materiales que pueden deducirse de la legislación vigente, por lo que, la ausencia de legislación básica "[...] no impide a las Comunidades Autónomas ejercer su competencia legislativa siempre que se respeten las bases o normas básicas entendidas como nociones materiales que se deduzcan racionalmente de la legislación vigente, estén o no formuladas de forma expresa, y sin perjuicio de que el Estado pueda dictar en el futuro tales normas, que, naturalmente, serán entonces aplicables a las Comunidades Autónomas" (FJ 5) 56 .

En ausencia de bases estatales en esta materia, es constitucionalmente admisible que Catalunya apruebe una Ley de cambio climático y fije objetivos de

${ }^{56}$ STC 64/1982, de 4 de noviembre. 
reducción de emisiones con carácter vinculante tomando directamente como base los parámetros establecidos por la Unión Europea en este ámbito, sin perjuicio de que la legislación autonómica deba adaptarse a las bases estatales cuando éstas se aprueben y quede desplazada en aquellos puntos en que las contradigan.

También debemos señalar el título competencial atribuido al Estado sobre "las bases y la coordinación de la planificación general de la actividad económica" (art. 149.1.13 CE), el cual no justifica la centralización de la competencia en la materia de cambio climático ${ }^{57}$. En relación a este título competencial, es importante destacar que el Estado español frecuentemente ha invocado la incidencia económica que tienen las políticas en materia de cambio climático como argumento para blindar las competencias autonómicas en este ámbito ${ }^{58}$.

No obstante, cabe recordar que la jurisprudencia constitucional utiliza un criterio restrictivo de interpretación del mencionado título competencial, con la finalidad de impedir una aplicación indiscriminada que provoque un vacío de las competencias autonómicas. Así, el Alto Tribunal introduce la regla de la

\footnotetext{
57 En un sector en el que confluyen la economía y la protección del medio ambiente -el Fondo de Carbono- el Tribunal Constitucional se ha decantado por encuadrar las normas impugnadas en el ámbito competencial del medio ambiente, por cuanto considera más específica la regla competencial del art. 149.1.23 CE. Véase las SSTC 91/2017, de 6 de julio; 15/2018, de 22 de febrero; 62/2018, de 7 de junio y 64/2018, de 7 de junio. Una de las cuestiones objeto de controversia en las citadas sentencias, es si la reserva al Estado de las competencias ejecutivas se puede justificar desde un punto de vista constitucional. Sobre esto el Tribunal Constitucional desestima las impugnaciones planteadas amparándose en la necesidad de una dirección y organización unitaria del mismo, que impide la asunción de competencias decisorias por parte de las Comunidades Autónomas en dicha gestión.

Para un analisis de estas sentencias, véase BLASCO HEDO, E., "Sentencia 91/2017 del Pleno del Tribunal Constitucional, de 6 de julio de 2017 (Ponente: Alfredo Montoya Melgar)", Actualidad Jurídica Ambiental, núm. 72, octubre de 2017, pp. 48-50. BLASCO HEDO, E., "Sentencia 15/2018 del Pleno del Tribunal Constitucional, de 25 de enero de 2018 (Ponente: Ricardo Enríquez Sancho)", Actualidad Jurídica Ambiental, 10 de abril de 2018. $<$ http://www.actualidadjuridicaambiental.com/jurisprudencia-al-dia-tribunal-constitucional-fondodel-carbono-cambio-climatico/> [Última consulta, 12 de noviembre de 2018]). BLASCO HEDO, E., "Sentencia 62/2018 del Pleno del Tribunal Constitucional, de 7 de junio de 2018 (Ponente: Encarnación Roca Trías)", Actualidad Jurídica Ambiental, núm. 82, septiembre de 2018, pp.138143. BLASCO HEDO, E., "Sentencia 64/2018 del Pleno del Tribunal Constitucional, de 7 de junio de 2018 (Ponente: Juan Antonio Xiol Ríos)", Actualidad Jurídica Ambiental, núm. 82, septiembre de 2018, pp. 144-149. CASADO CASADO, L., La recentralización de competencias en materia de protección del medio ambiente, Generalitat de Catalunya, Institut d'Estudis de l'Autogovern, Barcelona, 2018, pp. 314-327.

${ }^{58}$ Sobre el tema de la recentralización competencial en medio ambiente vid. CASADO CASADO, L., La recentralización de competencias en materia de protección del medio ambiente, Generalitat de Catalunya, Institut d'Estudis de l'Autogovern, Barcelona, 2018.
} 
incidencia directa y significativa sobre la actividad económica general como criterio para determinar la legitimidad constitucional del título 149.1.13 CE ${ }^{59}$.

En consecuencia, en el caso que nos ocupa, consideramos que el artículo 149.1.13 CE no permite justificar que la definición de los objetivos propios de reducción de emisiones de GEI y los instrumentos necesarios en el ámbito de la adaptación, tengan una incidencia directa y significativa sobre la actividad económica general en los términos establecidos por la jurisprudencia constitucional. Por lo tanto, la utilización del artículo 149.1.13 CE para justificar la competencia estatal excede de las competencias que la propia Constitución le atribuye.

\section{CONCLUSIONES}

El camino iniciado en Catalunya desde hace años en materia de cambio climático, da como resultado la Ley 16/2017, de 1 de agosto, del cambio climático. Esta Ley es fruto de la madurez de la política catalana y de una responsabilidad coherente con las iniciativas de la Unión Europea y con los instrumentos internacionales sobre cambio climático.

Con la aprobación de esta Ley, Catalunya refuerza una posición de liderazgo tanto en el ámbito interno del Estado español como en el ámbito internacional. De este modo, la Ley de cambio climático reitera la corresponsabilidad para cumplir con los objetivos climáticos desde dentro y fuera del Gobierno y solicita a todas las autoridades ejecutorias que integren los objetivos climáticos en sus actividades. Constituye un paso muy importante para establecer los fundamentos legales de la política de reducción de las emisiones de gases con efecto invernadero - mitigación - y de reducción de la vulnerabilidad ante los efectos del cambio climático —adaptación-.

La Ley de cambio climático plantea, a largo plazo, la transición hacia una sociedad resiliente y neutra en carbono, y proporciona un conjunto de medidas, principalmente normativas y fiscales. También se establece una base de responsabilidad transparente para la integración y la coordinación de la política

59 Vid. STC 102/1995, de 26 de junio. 
climática. Se debe reconocer que el texto es ambicioso en muchos aspectos y que presenta una coherencia interna. Así, esta Ley contiene elementos a destacar favorablemente como: el objetivo de neutralidad del carbono legalmente vinculante para el año 2050, juntamente con un suministro de energía $100 \%$ renovable para el mismo año; y el objetivo de alcanzar el año 2030 el 60\% de reducción de emisiones en comparación con los niveles de 2005. Además, disponer de una norma con rango de ley ofrece grandes ventajas, siempre y cuando se cumplan los compromisos adoptados por medio de esta norma.

No obstante, hay aspectos a mejorar de esta norma. En primer lugar, la Ley debería abordar un sistema de estructuras de control y de rendición de cuentas. En segundo lugar, se debería incluir un soporte a los responsables sectoriales y del territorio en forma de conocimiento y de información rigurosa para afrontar los retos técnicos y políticos intersectoriales, así como un sistema uniforme de métricas que admita el diseño, la implementación y la evaluación de medidas ${ }^{60}$. Además, de manera similar al Acuerdo de París, el enfoque de los diferentes actores debería ser de abajo arriba, creando las sinergias y los compromisos adecuados.

Así, se necesitará voluntad política y astucia técnica para materializar todo el potencial de las medidas que incorpora la Ley, como la integración de la política climática en políticas sectoriales y la acción climática asignada al mismo Gobierno y a sus instalaciones. En este contexto, la palabra "compromiso" es clave para que esta Ley sea verdaderamente efectiva y se convierta en el motor del cambio. Pero este compromiso no es solo por parte de todos los departamentos de la Generalitat, sino también de la sociedad civil.

En estos momentos, todavía no se ha podido ejecutar la Ley, por estar suspendida como consecuencia de la impugnación ante el Tribunal Constitucional promovida por el Gobierno del Estado, dentro de su línea de actuación centralizadora. Por ello, todavía no podemos apreciar si hay una correspondencia de los resultados con las expectativas que el articulado ha generado. Por tanto, se deberá esperar para comprobar que los esfuerzos para aplicarla sean los que requiere, que se le asignen los recursos necesarios, que

60 TORRES, M., "La Llei del canvi climàtic, entre les més ambicioses del món”, Eines, núm. 30, 2018, p. 88. 
se comunique adecuadamente a los ciudadanos y que, en suma, consiga ser un auténtico revulsivo para las políticas sectoriales actuales, que no integran el fenómeno del cambio climático.

La Ley de cambio climático es una oportunidad y una base jurídica para afrontar la transición hacia una sociedad resiliente y baja en carbono.

\section{BIBLIOGRAFÍA}

ABBAS, MEDÍ, "Politiques de I'Union. La proposition d'une taxe $\mathrm{CO} 2$ aux frontières. Vers une stratégie européenne en matière de régulation commerciale et de lutte contre le changement climatique?", Revue du marche commun et de l'Union Européenne, 2007, núm. 513, pp. 628-637.

ALENZA GARCÍA, J. F., “¿Hacia un marco jurídico común de energías renovables y cambio climático?", RIVERO ORTEGA, R., RASTROLLO SUÁREZ, J. J. (coords.), Actas del XI Coloquio Hispano-Portugués de Derecho Administrativo, Salamanca, Universidad de Salamanca, 2014, pp. 137-145.

ALENZA GARCíA, J. F., (dir.), La regulación de las energías renovables ante el cambio climático, Cizur Menor, Thomson Reuters Aranzadi, 2015.

ALVAREZ FERNÁNDEZ, M., "Las políticas públicas frente al cambio climático: el Plan Nacional de Asignación de Derechos de Emisión de Gases de Efecto Invernadero", Noticias de la Unión Europea, 2007, núm. 271-272, pp. 59-80.

BAÑo LEÓN, J. M., REVUELTA PÉREZ, I., "Cambio climático y Administración local", Revista Democracia y Gobierno Local, núm. 33, 2016, pp. 5-11.

BLASCO HEDO, E., "Sentencia 91/2017 del Pleno del Tribunal Constitucional, de 6 de julio de 2017 (Ponente: Alfredo Montoya Melgar)", Actualidad Jurídica Ambiental, núm. 72, octubre de 2017, pp. 48-50.

BLASCO HEDO, E., "Sentencia 15/2018 del Pleno del Tribunal Constitucional, de 25 de enero de 2018 (Ponente: Ricardo Enríquez Sancho)", Actualidad Jurídica Ambiental, 10 de abril de 2018. $<$ http://www.actualidadjuridicaambiental.com/jurisprudencia-al-dia-tribunalconstitucional-fondo-del-carbono-cambio-climatico/> [Última consulta, 12 de noviembre de 2018]). 
BLASCO HEDO, E., "Sentencia 62/2018 del Pleno del Tribunal Constitucional, de 7 de junio de 2018 (Ponente: Encarnación Roca Trías)", Actualidad Jurídica Ambiental, núm. 82, septiembre de 2018, pp.138-143.

BLASCO HEDO, E., "Sentencia 64/2018 del Pleno del Tribunal Constitucional, de 7 de junio de 2018 (Ponente: Juan Antonio Xiol Ríos)", Actualidad Jurídica Ambiental, núm. 82, septiembre de 2018, pp. 144-149.

BORRÀS PENTINAT, S., "Ciudades y cambio climático: responsabilidades, retos y oportunidades", Revista Democracia y Gobierno Local, núm. 33, 2016, pp. 1214.

CASADO CASADO, L., La recentralización de competencias en materia de protección del medio ambiente, Generalitat de Catalunya, Institut d'Estudis de l'Autogovern, Barcelona, 2018.

DE LA CRUZ LEIVA, J. L., "La transición hacia una economía baja en carbono: una oportunidad para el clima y el empleo". Administración \& ciudadanía: revista da Escola Galega de Administración Pública, vol. 11, núm. 2, 2016, pp. 281-304. FAJARDO DEL CASTILLO, T., "El acuerdo de París sobre el cambio climático: sus aportaciones al desarrollo progresivo del Derecho internacional y las consecuencias de la retirada de los Estados Unidos", Revista española de derecho internacional, vol. 70, núm. 1, 2018, pp. 23-51.

FAUTH, G., RODRÍGUEZ BEAS, M., "Políticas de adaptación al cambio climático: especial referencia al pacto de alcaldes", en BORRÀS PENTINAT, S., VILLAVICENCIO CALZADILLA, P. (coord.), Retos y Realidades de la Adaptación al Cambio Climático. Perspectivas técnico-jurídicas, Aranzadi, Navarra, 2013, pp. 237-262.

GALÁN VIOQUE, R., GONZÁLEZ RíOS, I., Derecho de las energías renovables y la eficiencia energética en el horizonte 2020, Pamplona, Aranzadi, 2017.

GALERA RODRIGO, S., GÓMEZ ZAMORA, M. M. (coord.), Políticas locales de clima y energía. Teoría y práctica. Instituto Nacional de Administración Pública, 2018.

GARCÍA LUPIOLA, A., "La política medioambiental de la unión europea ante el cambio climático", Revista Electrónica de Derecho Ambiental, 2009, núm. 18. 
GONZÁLEZ RíOS, I., ÁVILA RODRíGUEZ, C. M., (coords.), Estudios sobre la normativa reguladora de la eficiencia energética. Especial referencia a su incidencia en las Administraciones públicas, Madrid, Thomson ReutersAranzadi, 2016.

JIMÉNEZ HERRERO, L. M., "El Acuerdo climático de París: bases para una descarbonización profunda en una perspectiva europea y española", Administración \& ciudadanía: revista da Escola Galega de Administración Pública, vol. 11, núm. 2, 2016, pp. 227-242.

LABANDEIRA VILLOT, X., "Cambio climático: el camino desde París", Administración \& ciudadanía: revista da Escola Galega de Administración Pública, vol. 11, núm. 2, 2016, pp. 221-224.

LAGO CANDEIRA, A., "Compromisos Internacionales ambientales: Agenda 2030 y Objetivos de Desarrollo Sostenible (incluidos los de cambio climático)", LÓPEZ RAMÓN, F. (coord.), Observatorio de políticas ambientales 2016, Centro de Investigaciones Energéticas, Medioambientales y Tecnológicas, CIEMAT, 2016, pp. 25-64.

LAGO CANDEIRA, A., "El Acuerdo de París. ¿Solución al cambio climático o el principio del fin del actual multilateralismo ambiental?, Ambienta: La revista del Ministerio de Medio Ambiente, núm. 114, 2016, pp. 20-32.

MOVILLA PATEIRO, L., "2015, Un año clave a nivel internacional para el desarrollo sostenible, el cambio climático y el agua", Revista de derecho, agua y sostenibilidad, 2016, núm. 0, pp. 1-8.

NAVARRO RODRÍGUEZ, P., MORENO REBATO, M., "Nuevas medidas locales de lucha contra el cambio climático, especialmente en Andalucía", Revista de derecho urbanístico y medio ambiente, núm. 51, 2017, pp. 113-139.

NAVARRO RODRÍGUEZ, P., "Regulación autonómica de la lucha contra el cambio climático: entre Cataluña, País Vasco y Andalucía", El Cronista del Estado Social y Democrático de Derecho, núm. 75, 2018, pp. 22-27.

OLABE EGAÑA, A., "Tras el Acuerdo de París: elementos para una estrategia de salida a la crisis del clima", Administración \& ciudadanía: revista da Escola Galega de Administración Pública, vol. 11, núm. 2, 2016, pp. 263-280. 
PAREJO ALFONSO, L., (dir.), El Derecho Ante la Innovación y los Riesgos Derivados del Cambio Climático, Valencia, Tirant lo Blanch, 2015.

PONT I CASTEJÓN, I.; CAMPINS ERITJA, M.; NIETO MORENO, J. E., "Epíleg jurídic: De Kyoto a París. Escenaris i reptes futurs en la política internacional de canvi climàtic", Tercer informe sobre el canvi climàtic a Catalunya, Generalitat de Catalunya, Institut d'estudis catalans, Barcelona, 2016, pp. 597-612.

RUIZ DE ELVIRA, A., "Contra el cambio climático, un cambio de mente", Ambienta: La revista del Ministerio de Medio Ambiente, núm. 114, 2016.

SALINAS ALCEGA, S., "El Acuerdo de París de diciembre de 2015: la sustitución del multilateralismo por la multipolaridad en la cooperación climática internacional", Revista española de derecho internacional, vol. 70, núm. 1, 2018, pp. 53-76.

SANZ RUBIALES, Í., (coord.), Cambio climático y Unión Europea, Valencia, Tirant lo Blanch, 2014.

SARASÍBAR IRIARTE, M., "La Cumbre del Clima de París: ¿un avance importante en la política del cambio climático?, Administración \&ciudadanía: revista da Escola Galega de Administración Pública, vol. 11, núm. 2, 2016, pp. 307-314.

TORRES, M., "La Llei del canvi climàtic, entre les més ambicioses del món", Eines, núm. 30, 2018.

YÁBAR STERLING, A., "Mecanismos de consulta, participación y cooperación para una estrategia española de cambio climático", $M+A$, revista electrónica de medioambiente, 2006, núm. 2.

VERDÚ BAEZA, J. "Retos para España y la Unión Europea en la lucha contra el cambio climático: el complicado camino hacia París 2015. Nuevos paradigmas de cooperación transfronteriza en el Estrecho", ALCAIDE FERNÁNDEZ, J.; PETIT DE GABRIEL, E. (coords.), España y la Unión Europea en el orden internacional: XXVI Jornadas ordinarias de la Asociación Española de Profesores de Derecho internacional y Relaciones internacionales, Universidad de Sevilla, 15 y 16 de octubre de 2015. 
VERDÚ BAEZA, J., "A propósito de la cumbre climática de Marrakech: Cuando la solución empieza a ser parte del problema", Revista electrónica de estudios internacionales, núm. 33, 2017. 